\title{
Impact of combined losartan/hydrochlorothiazide on proteinuria in patients with chronic kidney disease and hypertension
}

\author{
Kiichiro Fujisaki ${ }^{1,8}$, Kazuhiko Tsuruya ${ }^{1,2,8}{ }^{\text {, Toshiaki Nakano }}{ }^{1}$, Masatomo Taniguchi ${ }^{1}$, Harumichi Higashi ${ }^{3}$, \\ Ritsuko Katafuchi ${ }^{4}$, Hidetoshi Kanai ${ }^{5}$, Masaru Nakayama ${ }^{6}$, Hideki Hirakata ${ }^{7}$ and Takanari Kitazono ${ }^{1}$ \\ on behalf of Impact of Combined Losartan/Hydrochlorothiazide on Proteinuria in Patients with Chronic \\ Kidney Disease and Hypertension (ILOHA) Study Investigators
}

It is unknown whether the use of diuretics is optimal over other antihypertensive agents in patients with chronic kidney disease (CKD) whose blood pressure remains uncontrolled despite treatment with renin-angiotensin system (RAS) inhibitors. In this study, we assessed the additive effects of hydrochlorothiazide (HCTZ) on reducing proteinuria in CKD patients under treatment with losartan (LS). We conducted a multicenter, open-labeled, randomized trial. One hundred and two CKD patients with hypertension and overt proteinuria were recruited from nine centers and randomly assigned to receive either LS $(50 \mathrm{mg}, n=51)$ or a combination of LS ( $50 \mathrm{mg}$ per day) and HCTZ ( $12.5 \mathrm{mg}$ per day) (LS/HCTZ, $n=51)$. The primary outcome was a decrease in the urinary protein-to-creatinine ratio (UPCR). The target blood pressure was $<130 / 80 \mathrm{~mm} \mathrm{Hg}$, and antihypertensive agents (other than RAS inhibitors and diuretics) were added if the target was not attained. Baseline characteristics of the two groups were similar. After 12 months of treatment, decreases in the UPCR were significantly greater in the LS/HCTZ group than in the LS group. There were no significant differences in blood pressure or the estimated glomerular filtration rate between the two groups. LS/HCTZ led to a greater reduction in proteinuria than treatment with LS, even though blood pressure in the LS group was similar to that in the LS/HCTZ group following the administration of additive antihypertensive agents throughout the observation period. This finding suggests that LS/HCTZ exerts renoprotective effects through a mechanism independent of blood pressure reduction.

Hypertension Research (2014) 37, 993-998; doi:10.1038/hr.2014.110; published online 26 June 2014

Keywords: angiotensin II type 1 receptor blocker; chronic kidney disease; hydrochlorothiazide

\section{INTRODUCTION}

Data from many large-scale clinical trials demonstrate that reninangiotensin system (RAS) inhibitors such as angiotensin-converting enzyme inhibitor (ACEI) and angiotensin II type 1 receptor blocker (ARB) have an evident effect on kidney protection. ${ }^{1-5}$ Recent guidelines on hypertension management ${ }^{6,7}$ recommend the concomitant use of several types of antihypertensive drugs when the target blood pressure is not reached. The guidelines recommended the strict control of blood pressure in patients with chronic kidney disease (CKD) with a complication of hypertension; however, the appropriate target value of blood pressure decline is almost never reached using a single RAS inhibitor.
In various combined therapies, the combined use of RAS inhibitors such as ARB or ACEI and calcium channel blocker (CCB) or small amounts of thiazide diuretics has been determined as being effective. However, whether to select CCB or diuretics for concomitant use following RAS inhibitor is clinically an important consideration. The appropriate approach was verified by the GUARD study ${ }^{8}$ and the ACCOMPLISH study. ${ }^{9} 10$ Subjects of the GUARD study were diabetic nephropathy patients. Subjects of the ACCOMPLISH study were patients at high risk of cardiovascular events. Both studies compared and verified the therapeutic effects when amlodipine (a CCB) or hydrochlorothiazide (HCTZ) (a diuretic) was concomitantly used with ACEI. Although HCTZ reduced albuminuria in both studies,

${ }^{1}$ Department of Medicine and Clinical Science, Graduate School of Medical Sciences, Kyushu University, Fukuoka, Japan; ${ }^{2}$ Department of Integrated Therapy for Chronic Kidney Disease, Graduate School of Medical Sciences, Kyushu University, Fukuoka, Japan; ${ }^{3}$ Department of Nephrology, St Mary's Hospital, Kurume, Japan; ${ }^{4}$ Kidney Unit, National Fukuoka Higashi Medical Center, Koga, Japan; ${ }^{5}$ Division of Nephrology, Kokura Memorial Hospital, Kitakyushu, Japan; ${ }^{6}$ Division of Nephrology and Clinical Research Institute, Department of Internal Medicine, National Kyushu Medical Center Hospital, Fukuoka, Japan and ${ }^{7}$ Division of Nephrology and Dialysis Center, Japanese Red Cross Fukuoka Hospital, Fukuoka, Japan

8These authors contributed equally to this work.

Correspondence: Dr K Tsuruya, Department of Integrated Therapy for Chronic Kidney Disease, Graduate School of Medical Sciences, Kyushu University, 3-1-1 Maidashi, Higashi-ku, Fukuoka 812-8582, Japan.

E-mail: tsuruya@intmed2.med.kyushu-u.ac.jp

Received 19 January 2014; revised 18 April 2014; accepted 22 May 2014; published online 26 June 2014 
there was also a large decline in the estimated glomerular filtration rate (eGFR). In the ACCOMPLISH study, a significantly large number of cardiovascular events were generated in the HCTZ group, and the renal prognosis was also better in the CCB group. However, only a few patients exhibited overt albuminuria in both studies, and the declining rate of renal function in the patient group was also very slow.

There are no clinical studies to date comparing the effects of diuretics and the other antihypertensive agents on reducing urinary protein under treatment with ARBs and comparable blood pressure control in CKD patients with overt proteinuria. Therefore, we conducted a prospective, randomized, open-labeled, multicenter trial to determine the efficacy of a fixed-dose combination of losartan (LS) plus HCTZ and a normal dose of LS in patients with CKD and hypertension.

\section{METHODS}

The present study was a 1-year prospective, randomized, open-labeled, parallel-group, multicenter trial. The objective was to elucidate the renoprotective effects of ARB/low-dose HCTZ combination therapy on CKD patients with proteinuria and hypertension.

The protocol was approved by the Independent Review Board of Kyushu University Hospital (No. 0272) and registered at UMIN-CTR (ID: UMIN000001643). The institutional review boards or ethics committees of all participating institutions approved the study protocol. All patients provided written informed consent.

\section{Study population}

Target patients were outpatients with systolic blood pressure (SBP) $>130 \mathrm{~mm}$ $\mathrm{Hg}$ and/or diastolic blood pressure (DBP) $>80 \mathrm{~mm} \mathrm{Hg}$, or taking antihypertensive drugs at the time when consent was obtained. The following conditions were also required: (1) the urinary protein $\left(\mathrm{mg} \mathrm{dl}^{-1}\right) /$ creatinine $\left(\mathrm{mg} \mathrm{dl}^{-1}\right)$ ratio (UPCR) for the 8 weeks before the study commencing exceeded 0.3 ( $\mathrm{g} \mathrm{g}^{-1} \mathrm{Cr}$ ); (2) eGFR was $15 \mathrm{ml} \mathrm{min}^{-1}$ per $1.73 \mathrm{~m}^{2}$ or more; and (3) patients were aged between 20 and 74 years old. Exclusion criteria were: (1) patients with hepatic dysfunction (e.g., when alanine aminotransferase exceeded the normal upper limit by threefold or more); (2) patients who had a myocardial infarction or apoplexy in the previous 3 months; (3) patients who were or might be pregnant; (4) patients with the possibility of becoming pregnant within the study period and patients who were breastfeeding; (5) patients with a serious nephrotic syndrome (serum albumin $<2 \mathrm{~g} \mathrm{dl}^{-1}$ ); (6) immunoglobulin A (IgA) nephropathy patients within a year from commencing steroid therapy; (7) patients with hyperkalemia $\left(5.5 \mathrm{mEql}^{-1}\right.$ or more); and (8) patients undergoing thiazide diuretics or thiazide-like diuretics administration.

\section{Study design}

Eligible patients were randomly assigned in a 1:1 ratio to receive either LS ( $50 \mathrm{mg}$ per day) or LS (50 mg per day) and HCTZ ( $12.5 \mathrm{mg}$ per day) combination therapy, each of which was administered once every morning. A $50 \mathrm{mg}$ LS/12.5 mg HCTZ combination tablet was used for combination therapy. On the day of randomization, initial evaluations (medical history and medication), assessments of clinic blood pressure and laboratory tests (blood and urine) were performed after written informed consent was obtained. Figure 1 shows the study design.

ACEI or ARB administered to patients at the time of obtaining consent $(-1 \mathrm{M})$ was changed to LS $(50 \mathrm{mg}$ per day). LS ( $50 \mathrm{mg}$ per day) was additionally administered to patients who were not taking ACEI or ARB. LS ( $50 \mathrm{mg}$ per day) was continued when allotted to the LS administration group at the time of commencing the allotment drug $(0 \mathrm{M})$, and when allotted to the diuretic administration group, LS was replaced with an LS/HCTZ combination drug. Blood pressure measurements and blood and urine collection were carried out throughout the study period. Antihypertensive drugs other than diuretics, ACEI and ARB, were added when blood pressure did not decline to $<130 / 80 \mathrm{mmHg}$. Blood pressure measurements and blood and urine

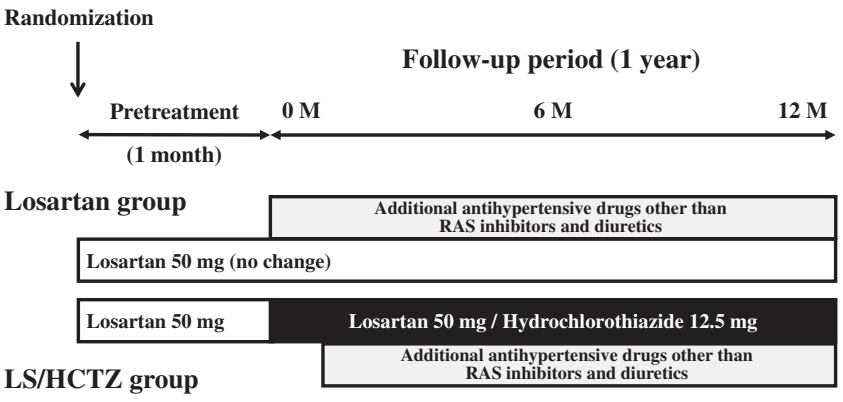

Figure 1 Study protocol. Blood pressure was targeted at $<130 / 80 \mathrm{~mm} \mathrm{Hg}$ during the study period. HCTZ, hydrochlorothiazide; LS, Iosartan; RAS, renin-angiotensin system.

collection were carried out at $0,1,2,4,6$ and 12 months following commencement of treatment.

Adverse events included intractable hypotension symptoms (e.g., fainting or dizziness), hyperkalemia (potassium $>6.0 \mathrm{mEql}^{-1}$ ), laboratory data abnormalities (e.g., acute worsening of kidney or liver function) and any side effects that required the discontinuation of medication to protect the patient's best interest.

\section{Measurements}

The levels of blood and urinary biochemical parameters and urinary protein excretion were measured in the hospital during consultations as outpatients. All assays were performed using commercially available laboratory equipment. Clinical blood pressure was measured using the auscultation method with a mercury sphygmomanometer after $5 \mathrm{~min}$ of rest in a seated position in the hospital. The UPCR was simultaneously estimated using casual urine samples. The eGFR was calculated according to the following formula from the Japanese Society of Nephrology: eGFR $\left(\mathrm{ml} \mathrm{min}^{-1}\right.$ per $\left.1.73 \mathrm{~m}^{2}\right)=194 \times($ serum creatinine $)^{-1.094} \times$ age $^{-0.287}(\times 0.739$, if female $) .{ }^{11}$ CKD was defined as an eGFR $<60 \mathrm{ml} \mathrm{min}^{-1}$ per $1.73 \mathrm{~m}^{2}$ and/or the presence of proteinuria.

\section{Study outcome}

The primary outcome was determined as the amount of change in the UPCR from the value before commencing treatment to 12 months following commencement of treatment between the two groups. The secondary outcome was the change in blood pressure and eGFR from the value at study commencement to 6 and 12 months following study commencement between the two groups.

\section{Sample size}

The planned sample size was 120 cases (60 cases in the LS group and 60 cases in the LS/HCTZ group). With reference to the report by Uzu et al. ${ }^{12}$ regarding the mean amount of change in urinary protein excretion before and after administration, the difference between CKD patients undergoing administration of ACEI or ARB and those undergoing administration of ACEI or ARB with concomitant use of thiazide was estimated at $0.2 \mathrm{~g}$ per day. The standard deviation of the amount of change was surmised to be approximately $0.35 \mathrm{~g}$ per day. When a Student's $t$-test was surmised with a difference in mean value of 0.2 , standard deviation of 0.35 , significance level of 0.05 (two-sided test) and statistical power of 0.80 , it was suggested that 50 cases were required for each group. We estimated that 10 to $20 \%$ cases would be discontinued/omitted during the study or found to be ineligible following registration, so the target number of cases was set at 60 cases for each group, totaling 120 cases.

\section{Statistical analysis}

Statistical analysis was performed using a commercially available software program (JMP statistics 9.0; SAS Institute, Tokyo, Japan). Data are expressed as the mean \pm s.d. or as a percentage. A $\chi^{2}$ test was applied to examine differences between prevalence in the two treatment groups. Data were analyzed based on the random allocation of participants to the treatment group regardless of the content of subsequent drug administration (intention-to-treat analysis). The 
mean value of both groups was compared using a Mann-Whitney $U$-test. Repeated measurement analysis of variance was used to evaluate the therapeutic effect against blood pressure, eGFR and uric acid level. $P<0.05$ was determined to be statistically significant.

\section{RESULTS}

Baseline characteristics

In this study, 102 cases ( $85 \%$ of the recommended sample size) satisfying the registration criteria were randomly allocated to the LS group $(n=51)$ or the LS/HCTZ group $(n=51)$ (Figure 2). Patients' backgrounds of the two groups at baseline are illustrated in Table 1, and there was no significant difference between the groups. In the LS group, three patients undergoing treatment were omitted from the protocol (initiation of hemodialysis: $n=1$; long hospitalization for malignant lymphoma: $n=1$; lost of follow-up: $n=1$ ), and postoperative follow-up as an outpatient could not be carried out for 12 months. Accordingly, these three patients were excluded as study subjects. In the LS/HCTZ group, seven patients were omitted from the protocol (acute worsening of kidney function: $n=3$; withdrawal of consent: $n=3$; skin eruption: $n=1$ ). However, it was possible to carry out postoperative follow-up as an outpatient for 12 months for all seven patients. Therefore, all 51 patients were included as study subjects.

The drugs taken during the study are shown in Table 2. In the losartan group, there were many cases in which CCB was additionally administered during the course, and the rate of internal use of CCB was significantly higher compared with the LS/HCTZ group.

\section{Changes in clinical blood pressure}

There were no differences in SBP or DBP between the two groups during the treatment period (Figure 3). SBP was $125.2 \pm 13.3 \mathrm{~mm} \mathrm{Hg}$ in the LS group and $124.9 \pm 15.3 \mathrm{~mm} \mathrm{Hg}$ in the LS/HCTZ group; DBP was $73.0 \pm 9.4 \mathrm{~mm} \mathrm{Hg}$ in the LS group and $74.1 \pm 8.6 \mathrm{~mm} \mathrm{Hg}$ in the LS/HCTZ group at 12 months following the commencement of treatment, with no significant difference between the two groups. The ratio of patients with blood pressure $<130 / 80 \mathrm{~mm} \mathrm{Hg}$ following 12 months was $50 \%$ in the LS group and $47 \%$ in the LS/HCTZ group, with no significant difference between the two groups.

\section{Changes in the UPCR}

At 6 and 12 months following commencement of the study, the amount of the UPCR decline in the LS/HCTZ group was significantly greater than that in the LS group (6 M: $0.21 \pm 0.99$ vs. -0.54 $\pm 0.73 \mathrm{~g} \mathrm{~g}^{-1} \mathrm{Cr}, P<0.05 ; 12 \mathrm{M}: 0.02 \pm 0.76$ vs. $-0.55 \pm 0.71 \mathrm{~g} \mathrm{~g}^{-1} \mathrm{Cr}$, $P<0.05$ ) (Figure $4 \mathrm{a}$ ). The relationship between $\mathrm{BP}$ reduction and the reduction in proteinuria is not significantly (Figures $4 \mathrm{~b}$ and $\mathrm{c}$ ).

\section{Changes in eGFR and uric acid}

The eGFR declined slightly more in the LS/HCTZ group compared with the LS group at 6 and 12 months following commencement of treatment; however, there was no significant difference between the two groups (6 M: LS $46.1 \pm 23.5 \mathrm{ml} \mathrm{min}^{-1}$ per $1.73 \mathrm{~m}^{2}$, LS/HCTZ $39.6 \pm 21.1 \mathrm{ml} \mathrm{min}^{-1}$ per $1.73 \mathrm{~m}^{2} ; 12 \mathrm{M}$ : LS $45.0 \pm 23.3 \mathrm{ml} \mathrm{min}^{-1}$ per $1.73 \mathrm{~m}^{2}, \mathrm{LS} / \mathrm{HCTZ} 40.5 \pm 21.7 \mathrm{ml} \mathrm{min}^{-1}$ per $1.73 \mathrm{~m}^{2}$ ) (Figure 5). The uric acid level following 12 months was significantly higher in the LS/HCTZ group (6.3 \pm 1.3 vs. $\left.7.1 \pm 1.4 \mathrm{mg} \mathrm{dl}^{-1}, P<0.05\right)$ (Figure 6).

\section{DISCUSSION}

The results of this study showed that combination therapy with LS/HCTZ led to a greater reduction in proteinuria than treatment with LS alone at the same blood pressure level. This study is the first to provide evidence to support the efficacy of LS/HCTZ combination therapy in patients, independent of antihypertensive effects. This finding suggests that the addition of diuretics constitutes an optimal treatment for patients with CKD under treatment with ARBs and that diuretics exert renoprotective effects through a mechanism independent of blood pressure reduction.

In addition to RAS inhibition, it is believed that strict blood pressure control has a major role in preventing the progression of renal disease. ${ }^{7,13,14}$ In this study, there was no difference between SBP and DBP in the two groups, with the average reaching the target blood pressure. In addition, there was no significant difference in the eGFR of both groups throughout the observational period of 1 year.

The following three points may be considered for the mechanism by which LS/HCTZ exhibited a urinary protein reducing effect in this study. The first point is the declining effect on blood pressure with

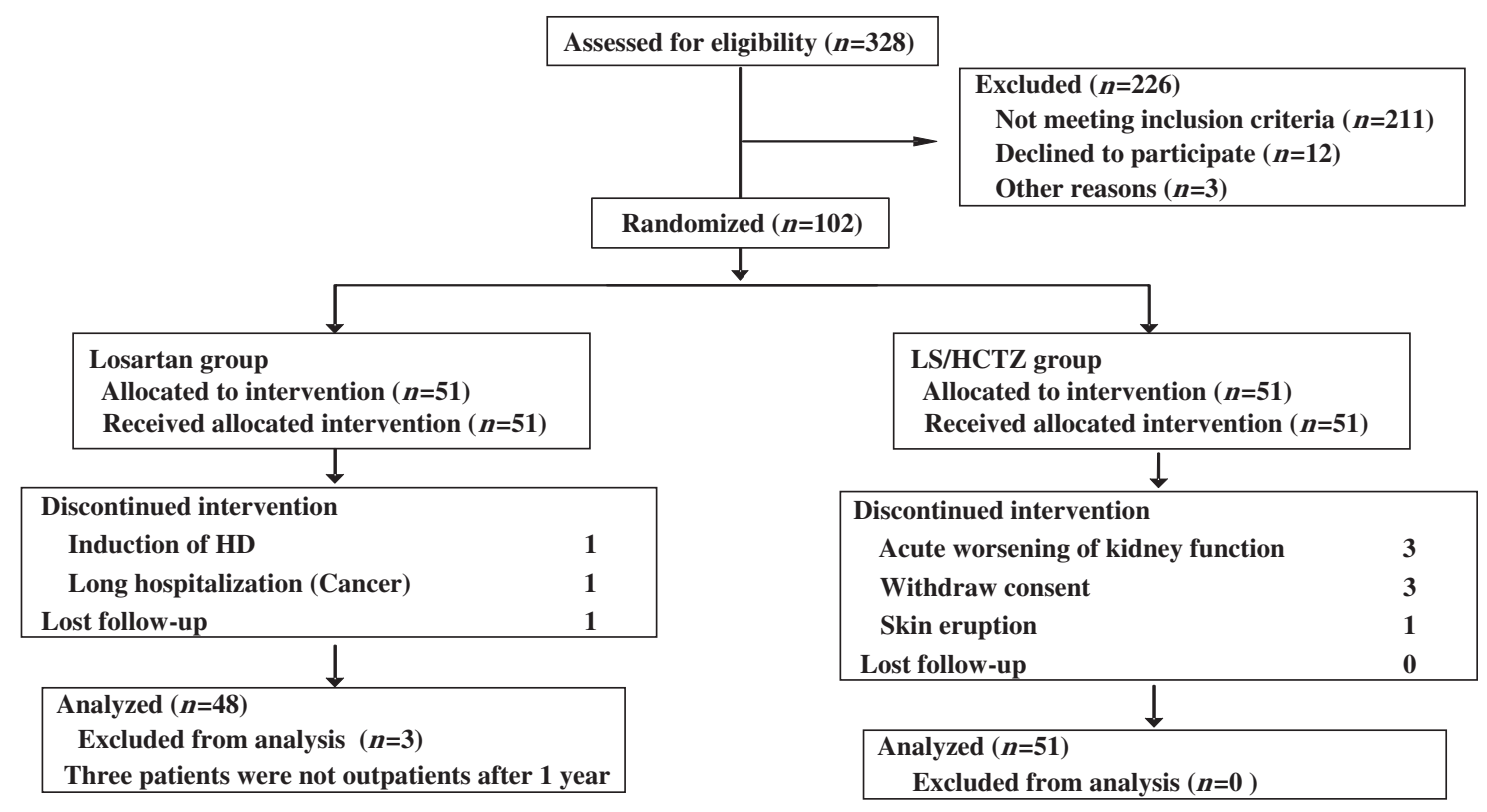

Figure 2 Flow chart of patient enrollment and follow-up. HCTZ, hydrochlorothiazide; HD, hemodialysis; LS, losartan. 
Table 1 Baseline characteristics

\begin{tabular}{|c|c|c|c|}
\hline & $\begin{array}{l}\text { Losartan } \\
\text { group }\end{array}$ & $\begin{array}{c}\text { LS/HCTZ } \\
\text { group }\end{array}$ & P-value \\
\hline Number $(n)$ & 48 & 51 & \\
\hline Age (year) & $58 \pm 12$ & $58 \pm 11$ & 0.90 \\
\hline Sex (male/female) & $26 / 22$ & $30 / 21$ & 0.61 \\
\hline \multicolumn{4}{|l|}{ Underlying kidney disease, n (\%) } \\
\hline Glomerulonephritis & $39(81)$ & $41(80)$ & 0.82 \\
\hline Diabetic nephropathy & $4(8)$ & $6(12)$ & \\
\hline Hypertensive nephrosclerosis & $5(11)$ & $5(8)$ & \\
\hline Systolic blood pressure (mm Hg) & $132 \pm 14$ & $128 \pm 13$ & 0.16 \\
\hline Diastolic blood pressure $(\mathrm{mm} \mathrm{Hg})$ & $77 \pm 9$ & $77 \pm 12$ & 0.84 \\
\hline Pulse rate (beats $\min ^{-1}$ ) & $73 \pm 10$ & $73 \pm 11$ & 0.82 \\
\hline Total protein $\left(\mathrm{gdl}^{-1}\right)$ & $6.9 \pm 0.6$ & $6.9 \pm 0.5$ & 0.55 \\
\hline Albumin $\left(\mathrm{gdl}^{-1}\right)$ & $4.0 \pm 0.4$ & $3.9 \pm 0.4$ & 0.10 \\
\hline HDL-cholesterol (mg dl-1) & $65 \pm 35$ & $61 \pm 26$ & 0.73 \\
\hline LDL-cholesterol (mg dl-1) & $119 \pm 35$ & $112 \pm 27$ & 0.42 \\
\hline Triglycerides $\left(\mathrm{mg} \mathrm{dl}{ }^{-1}\right)$ & $157 \pm 83$ & $154 \pm 76$ & 0.83 \\
\hline Blood urea nitrogen $\left(\mathrm{mg} \mathrm{dl}^{-1}\right)$ & $24 \pm 11$ & $25 \pm 11$ & 0.74 \\
\hline Creatinine $\left(\mathrm{mg} \mathrm{dl}^{-1}\right)$ & $1.4 \pm 0.7$ & $1.5 \pm 0.7$ & 0.68 \\
\hline Uric acid $\left(\mathrm{mg} \mathrm{dl}^{-1}\right)$ & $6.6 \pm 1.4$ & $6.6 \pm 1.3$ & 0.89 \\
\hline Sodium $\left(m E q I^{-1}\right)$ & $138 \pm 2$ & $141 \pm 2$ & 0.18 \\
\hline Potassium $\left(\mathrm{mEq}^{-1}\right)$ & $4.6 \pm 0.5$ & $4.6 \pm 0.5$ & 0.82 \\
\hline Chloride $\left(\mathrm{mEq} \mathrm{I}^{-1}\right)$ & $106 \pm 2.6$ & $107 \pm 2.7$ & 0.34 \\
\hline Calcium (mg dl-1) & $9.2 \pm 0.4$ & $9.2 \pm 0.5$ & 0.70 \\
\hline Phosphate $\left(\mathrm{mg} \mathrm{dl}^{-1}\right)$ & $3.4 \pm 0.6$ & $3.3 \pm 0.6$ & 0.72 \\
\hline Aspartate aminotransferase $\left(\mathrm{UI}^{-1}\right)$ & $22 \pm 6.1$ & $21 \pm 5.2$ & 0.89 \\
\hline Alanine aminotransferase $\left(\mathrm{UI}^{-1}\right)$ & $20 \pm 9.3$ & $17 \pm 8.9$ & 0.14 \\
\hline Alkaline phosphatase $\left(\mathrm{UI}^{-1}\right)$ & $237 \pm 79$ & $225 \pm 65$ & 0.65 \\
\hline$\gamma$-Glutamyl transpeptidase $\left(\mathrm{UI}^{-1}\right)$ & $43 \pm 29$ & $38 \pm 37$ & 0.14 \\
\hline eGFR (ml min ${ }^{-1}$ per $\left.1.73 \mathrm{~m}^{2}\right)$ & $45.9 \pm 25.1$ & $43.8 \pm 21.9$ & 0.67 \\
\hline Urinary protein/creatinine ratio $\left(\mathrm{gg}^{-1} \mathrm{Cr}\right)$ & $1.80 \pm 1.63$ & $1.74 \pm 1.40$ & 0.52 \\
\hline \multicolumn{4}{|l|}{ Treatment during pretreatment period, $\mathrm{n}(\%)$} \\
\hline Ca channel blockers & $24(50)$ & $22(43)$ & 0.42 \\
\hline$\beta$-Blockers & $3(6)$ & $7(14)$ & 0.43 \\
\hline$\alpha$-Blockers & $2(4)$ & $1(2)$ & 0.51 \\
\hline Statins & $21(44)$ & $17(33)$ & 0.96 \\
\hline
\end{tabular}

Abbreviations: ACEI, angiotensin-converting enzyme inhibitor; ARB, angiotensin II type 1 receptor blocker; $\mathrm{Cr}$, creatinine; eGFR, estimated glomerular filtration rate; $\mathrm{HDL}$, high-density lipoprotein; LDL, low-density lipoprotein; LS, Iosartan; HCTZ, hydrochlorothiazide.

Data are presented as mean \pm s.d.

respect to nocturnal hypertension. It is thought that diuretics and salt restriction normalizes the circadian rhythm of blood pressure from non-dipper to dipper, thereby reducing the load on the circulatory system and further inhibiting cardiac events by concomitant use with RAS-inhibiting drugs. ${ }^{15,16}$ Buter et al. ${ }^{17}$ reported that the urinary protein reducing the effect of RAS inhibitors was stronger during the day than during the night. It was reported that diuretics and salt restrictions normalize the circadian rhythm of blood pressure from non-dipper to dipper type, ${ }^{18,19}$ and the decline in proteinuria by administering diuretics is largely dependent on the decline in nocturnal blood pressure. ${ }^{12}$

The second point is the corrective effect from a state of excessive salt. It has been verified that the salt load promotes local tissue RAS activation in the organ, leading to the development of organ dysfunction.

The third point is that diuretics are reported to have an antioxidant effect, and there is a possibility that renal injury may be improved via a decline in oxidative stress. Skalska et al. ${ }^{20}$ reported that patients
Table 2 Medications used during the follow-up period, $n$ (\%)

\begin{tabular}{lccc}
\hline & LS group & LS/HCTZ group & P-value \\
\hline Ca channel blocker & $34(68)$ & $25(49)$ & $<0.05$ \\
$\beta$-Blocker & $9(18)$ & $7(14)$ & NS \\
$\alpha$-Blocker & $3(6)$ & $1(2)$ & NS \\
Statin & $26(52)$ & $23(45)$ & NS \\
\hline
\end{tabular}

Abbreviations: HCTZ, hydrochlorothiazide; LS, Iosartan; NS, nonsignificant.

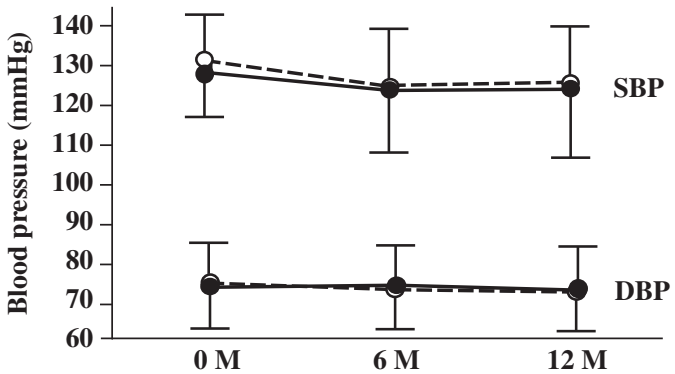

Figure 3 Changes in blood pressure during the study period. Systolic (SBP) and diastolic blood pressure (DBP) levels (mean \pm s.d.) at 0,6 and 12 months after treatment are shown. There were no differences in blood pressure between the losartan (LS) group (open circle and dash line) and the LS/hydrochlorothiazide (HCTZ) group (closed circle and solid line).

taking diuretics had significantly better antioxidative protection expressed by higher levels of the ferric-reducing ability of plasma.

To date, it has not been suggested that diuretics have an effect on renal protection. Rather, as serum creatinine increases with the administering of diuretics, it was once believed that it is a drug contributing to renal impairment. However, the results from this study suggest the possibility that an increase in serum creatinine and a decline in urinary protein content indicates a decline in intraglomerular pressure owing to diuretics, and that it has an effect on renal protection in the same manner as RAS inhibitors.

According to reports in the GUARD study ${ }^{8}$ and the ACCOMPLISH study, ${ }^{9,10}$ although HCTZ reduced albuminuria, the decline in eGFR was also very large. Unlike the subjects of the GUARD study and the ACCOMPLISH study, those of the current study were CKD patients showing overt proteinuria in which the eGFR advanced to approximately $40-45 \mathrm{ml} \mathrm{min}^{-1}$ per $1.73 \mathrm{~m}^{2}$. That is, the subjects were cases with a decreased functioning glomerulus count and increased intraglomerular pressure for each nephron unit. In such cases, diuretics used for a relatively long period of time such as HCTZ are believed to be effective for depression management, including management of the quantity of renal protecting body fluid as well as renal protection. It is possible that the result was affected because of Japanese people having a higher salt intake compared with Europeans and Americans. Excessive intake of salt causes excessive body fluid volume, attenuating the effect of ARB. It was hypothesized that excess extracellular fluid was discharged and a synergic effect due to concomitant use of ARB was induced by administering low-dose HCTZ to these patients.

From multiple clinical studies, proteinuria has been proven to be a predictive factor for the advancement of subsequent renal disease. According to a study by Lea et al., ${ }^{21}$ baseline proteinuria is independently related to the subsequent decline in GFR. Also, in recent years, albuminuria has been determined as being a risk factor to the cardiovascular system. In the Framingham study, proteinuria increased mortality threefold and was strongly related to other risk 
a

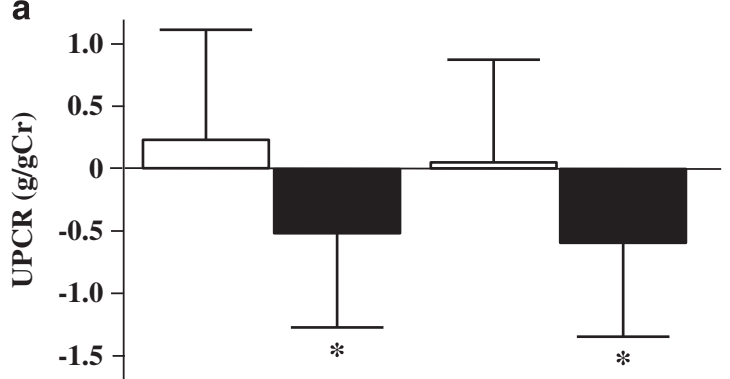

$6 \mathrm{M}$

$12 \mathrm{M}$
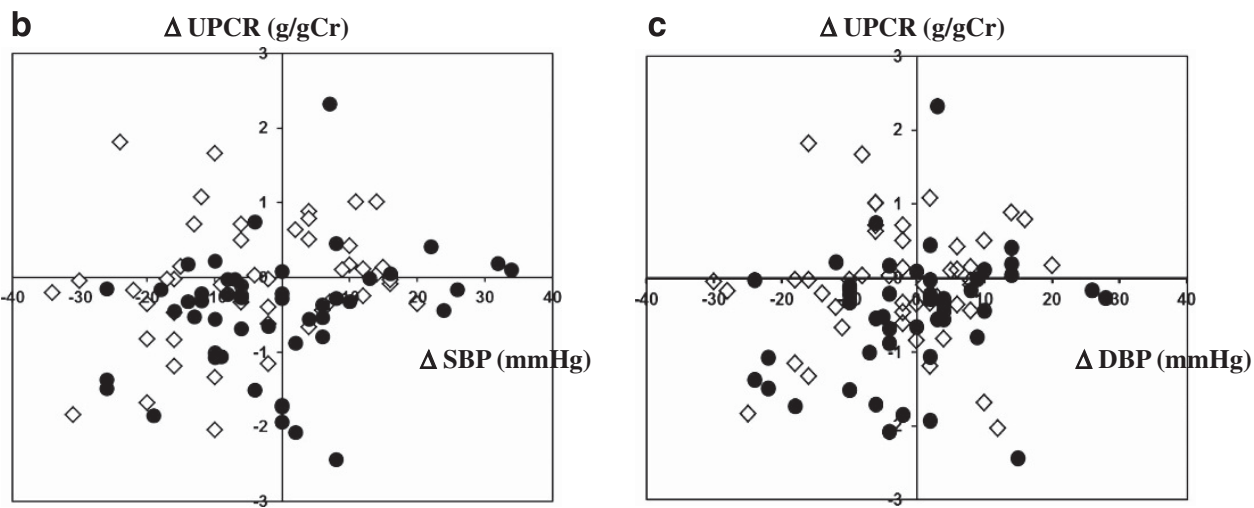

Figure 4 Changes in urinary protein-to-creatinine ratio (UPCR) and relationship between blood pressure (BP) reduction and the reduction in UPCR. (a) Mean changes in the UPCR ( $\mathrm{gg}^{-1} \mathrm{Cr}$ ) from baseline to 6 and 12 months in the losartan (LS) group (open column) and the LS/hydrochlorothiazide (HCTZ) group (closed column) are shown. ${ }^{*} P<0.05$ vs. the LS group. (b) The relationship between systolic blood pressure (SBP) reduction ( $\triangle \mathrm{SBP}$ ) and the reduction in UPCR ( $\triangle \mathrm{UPCR}$ ) from baseline to 12 months was not significant. (c) The relationship between diastolic blood pressure (DBP) reduction ( $\triangle \mathrm{DBP}$ ) and the reduction in UPCR ( $\triangle$ UPCR) from baseline to 12 months was not significant. Open square, the LS group; closed circle, the LS/HCTZ group.

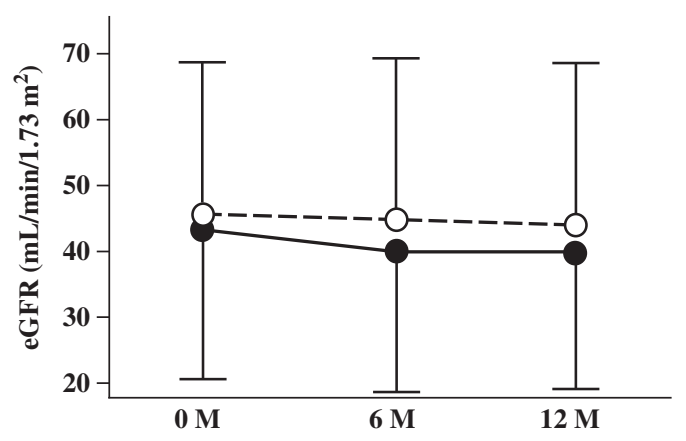

Figure 5 Changes in estimated glomerular filtration rate (eGFR) during the study period. The estimated GFR (mean \pm s.d.) values at 0,6 and 12 months after the start of treatment are shown. There were no differences in eGFR between the losartan (LS) group (open circle and dash line) and the LS/hydrochlorothiazide (HCTZ) group (closed circle and solid line).

factors for cardiovascular diseases. ${ }^{22}$ In the subanalysis for the Systolic Hypertension in Europe study, proteinuria was the predictive factor for the all-cause mortality and cardiovascular events. ${ }^{23}$ Data for basic and clinical studies to date have exhibited that renal failure and heart failure are suppressed once the proteinuria of CKD patients declines. ${ }^{24}$

In this study, 24-h urine collection was not carried out because it was too inconvenient and troublesome for outpatients. Twenty-four hour urine collection is the gold standard for urinary protein measurement, ${ }^{25}$ but it has been reported by several researchers that the UPCR of occasional urine exhibits a strong correlation with 1-day urinary protein excretion. ${ }^{26,27}$ The working group for the renal disease prognostic indicator of the National Kidney Foundation also reported

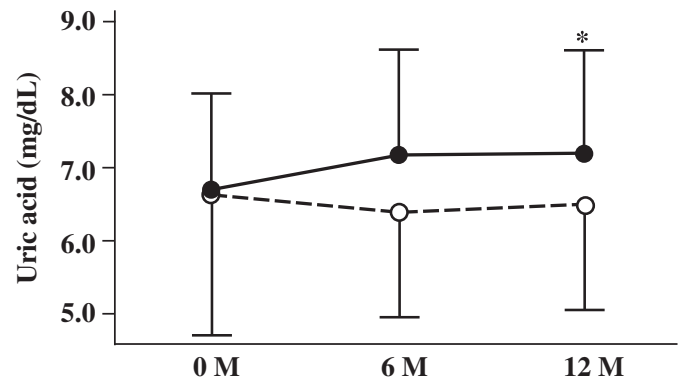

Figure 6 Changes in the uric acid levels during the study period. The uric acid (mean \pm s.d.) levels at 0,6 and 12 months after the start of treatment are shown. There was a significant difference in the uric acid levels at 12 months between the losartan (LS) group (open circle and dash line) and the LS/hydrochlorothiazide (HCTZ) group (closed circle and solid line). ${ }^{*} P<0.05$ vs. the LS group.

that the UPCR of first morning urine or spot urine is a test value suitable at clinical sites when evaluating the proteinuria in patients with renal disease. ${ }^{28}$

In this study, LS/HCTZ was discontinued in three patients in the LS/HCTZ group because of aggravation of renal function. Diuretics have a danger of aggravating renal function in patients on whom sodium restriction is being carried out or in patients with declined body fluid, so sufficient attention is required.

Our study has several limitations. Blood pressure was measured at an outpatient clinic, and no investigation into home blood pressure and 24-h ambulatory blood pressure monitoring was carried out. Therefore, the improvement effect of LS/HCTZ against nocturnal hypertension on the subjects of this study has not been evaluated and 
proved. Also, the sample size was $85 \%$ of the initially planned number of cases. However, we could find a significant difference in the primary outcome with the number of cases used in this study, because the difference in the amount of urinary protein was more than expected. Finally, the rate of use of CCB was significantly higher in the LS group than in the LS/HCTZ group. However, this bias did not appear to affect this result because the difference in the amount of urinary protein remained significant, even after adjustment for use of CCB.

In conclusion, in CKD patients with hypertension and overt proteinuria, the effect of reducing urinary protein was higher in the LS/HCTZ group than that in the LS group even when blood pressure was equivalently controlled. We believe that the concomitant use of $\mathrm{ARB}$ and thiazide diuretics should be considered for CKD patients with hypertension and overt proteinuria.

\section{CONFLICT OF INTEREST}

The authors declare no conflict of interest.

\section{ACKNOWLEDGEMENTS}

We thank the ILOHA study investigators: Masahiro Eriguchi, Akiko Fujisaki, Naoki Haruyama, Makoto Hirakawa, Tadashi Hirano, Kei Hori, Hirofumi Ikeda, Kiyoshi Ikeda, Takashi Inenaga, Hiroto Maeda, Rei Matsui, Koji Mitsuiki, Tohru Mizumasa, Hiroshi Nagae, Tadashi Nagara, Akinori Nagashima, Kaneyasu Nakagawa, Shotaro Onaka, Takaichi Suehiro, Koji Sugawara, Kazuhito Takeda, Shigeru Tanaka, Masanori Tokumoto, Jiro Toyonaga, Maki Toyonaga, Akihiro Tsuchimoto, Hiroshi Tsuruta, Shunsuke Yamada, Taihei Yanagida, Hisako Yoshida, Tetsuhiko Yoshida and Hideki Yotsueda. We also thank Kuniko Watanabe, Noriko Noda and Takako Noda for their secretarial assistance. We express our deep gratitude for the support of all physicians who kindly participated in this study. Without their support, the collection of real-world data would have been impossible.

Part of this study was presented at the 45th Annual Meeting of the American Society of Nephrology (San Diego, CA, USA, 2012).

1 Taguma Y, Kitamoto Y, Futaki G, Ueda H, Monma H, Ishizaki M, Takahashi H, Sekino H, Sasaki Y. Effect of captopril on heavy proteinuria in azotemic diabetics. New Engl J Med 1985; 313: 1617-1620.

2 Lewis EJ, Hunsicker LG, Bain RP, Rohde RD. The effect of angiotensin-convertingenzyme inhibition on diabetic nephropathy. The collaborative study group. New Eng/ J Med 1993; 329: 1456-1462.

3 Brenner BM, Cooper ME, de Zeeuw D, Keane WF, Mitch WE, Parving HH, Remuzzi G, Snapinn SM, Zhang Z, Shahinfar S for the RENAAL Study Investigators. Effects of losartan on renal and cardiovascular outcomes in patients with type 2 diabetes and nephropathy. New Engl J Med 2001; 345: 861-869.

4 Wright JT Jr, Bakris G, Greene T, Agodoa LY, Appel LJ, Charleston J, Cheek D, Douglas-Baltimore JG, Gassman J, Glassock R, Hebert L, Jamerson K, Lewis J, Phillips RA, Toto RD, Middleton JP, Rostand SG for the African American Study of Kidney Disease and Hypertension Study Group. Effect of blood pressure lowering and antihypertensive drug class on progression of hypertensive kidney disease: Results from the AASK trial. JAMA 2002; 288: 2421-2431.

5 Ruggenenti P, Perna A, Gherardi G, Garini G, Zoccali C, Salvadori M, Scolari F Schena FP, Remuzzi G. Renoprotective properties of ACE-inhibition in non-diabetic nephropathies with non-nephrotic proteinuria. Lancet 1999; 354: 359-364.

6 Mancia G, De Backer G, Dominiczak A, Cifkova R, Fagard R, Germano G, Grassi G, Heagerty AM, Kjeldsen SE, Laurent S, Narkiewicz K, Ruilope L, Rynkiewicz A, Schmieder RE, Boudier HA, Zanchetti A for the ESH-ESC Task Force on the Management of Arterial Hypertension. 2007 ESH-ESC Practice Guidelines for the Management of Arterial Hypertension: ESH-ESC Task Force on the Management of Arterial Hypertension. J Hypertens 2007; 25: 1751-1762.

7 Ogihara T, Kikuchi K, Matsuoka H, Fujita T, Higaki J, Horiuchi M, Imai Y, Imaizumi T, Ito $\mathrm{S}$, Iwao $\mathrm{H}$, Kario K, Kawano $\mathrm{Y}$, Kim-Mitsuyama S, Kimura G, Matsubara $\mathrm{H}$, Matsuura H, Naruse M, Saito I, Shimada K, Shimamoto K, Suzuki H, Takishita S, Tanahashi N, Tsuchihashi T, Uchiyama M, Ueda S, Ueshima H, Umemura S, Ishimitsu T, Rakugi H for the Japanese Society of Hypertension Committee. The Japanese Society of Hypertension Guidelines for the Management of Hypertension (JSH 2009). Hypertens Res 2009; 32: 3-107.

8 Bakris GL, Toto RD, McCullough PA, Rocha R, Purkayastha D, Davis P on behalf of the GUARD (Gauging Albuminuria Reduction With Lotrel in Diabetic Patients With
Hypertension) Study Investigators. Effects of different ACE inhibitor combinations on albuminuria: results of the GUARD study. Kidney Int 2008; 73: 1303-1309.

9 Jamerson K, Weber MA, Bakris GL, Dahlöf B, Pitt B, Shi V, Hester A, Gupte J, Gatlin M, Velazquez EJ for the ACCOMPLISH Trial Investigators. Benazepril plus amlodipine or hydrochlorothiazide for hypertension in high-risk patients. New Eng/ J Med 2008; 359: 2417-2428.

10 Bakris GL, Sarafidis PA, Weir MR, Dahlöf B, Pitt B, Jamerson K, Velazquez EJ, Staikos-Byrne L, Kelly RY, Shi V, Chiang YT, Weber MA for the ACCOMPLISH Trial Investigators. Renal outcomes with different fixed-dose combination therapies in patients with hypertension at high risk for cardiovascular events (ACCOMPLISH). A prespecified secondary analysis of a randomised controlled trial. Lancet 2010; 375 1173-1181.

11 Matsuo S, Imai E, Horio M, Yasuda Y, Tomita K, Nitta K, Yamagata K, Tomino Y, Yokoyama $\mathrm{H}$, Hishida $\mathrm{A}$. Revised equations for estimated GFR from serum creatinine in Japan. Am J Kidney Dis 2009; 53: 982-992.

12 Uzu T, Harada T, Namba T, Yamamoto R, Takahara K, Yamauchi A, Kimura G. Thiazide diuretics enhance nocturnal blood pressure fall and reduce proteinuria in immunoglobulin A nephropathy treated with angiotensin II modulators. J Hypertens 2005; 23: 861-865.

13 Mancia G, De Backer G, Dominiczak A, Cifkova R, Fagard R, Germano G, Grassi G, Heagerty AM, Kjeldsen SE, Laurent S, Narkiewicz K, Ruilope L, Rynkiewicz A, Schmieder RE, Boudier HA, Zanchetti A, Vahanian A, Camm J, De Caterina R, Dean V, Dickstein K, Filippatos G, Funck-Brentano C, Hellemans I, Kristensen SD, McGregor K, Sechtem U, Silber S, Tendera M, Widimsky P, Zamorano JL, Erdine S Kiowski W, Agabiti-Rosei E, Ambrosioni E, Lindholm LH, Viigimaa M, Adamopoulos S, Agabiti-Rosei E, Ambrosioni E, Bertomeu V, Clement D, Erdine S, Farsang C, Gaita D, Lip G, Mallion JM, Manolis AJ, Nilsson PM, O'Brien E, Ponikowski P, Redon J, Ruschitzka F, Tamargo J, van Zwieten P, Waeber B, Williams B, Management of Arterial Hypertension of the European Society of Hypertension; European Society of Cardiology: 2007 Guidelines for the Management of Arterial Hypertension. The Task Force for the Management of Arterial Hypertension of the European Society of Hypertension (ESH) and of the European Society of Cardiology (ESC). J Hypertens 2007; 25: 1105-1187.

14 Chobanian AV, Bakris GL, Black HR, Cushman WC, Green LA, Izzo JL Jr, Jones DW Materson BJ, Oparil S, Wright JT Jr, Roccella EJ, National Heart, Lung, and Blood Institute Joint National Committee on Prevention, Detection, Evaluation, and Treatment of High Blood Pressure; National High Blood Pressure Education Program Coordinating Committee. The Seventh Report of the Joint National Committee on Prevention, Detection, Evaluation, and Treatment of High Blood Pressure: the JNC 7 report. JAMA 2003; 289: 2560-2572.

15 Morimoto A, Uzu T, Fujii T, Nishimura M, Kuroda S, Nakamura S, Inenaga T, Kimura G. Sodium sensitivity and cardiovascular events in patients with essential hypertension. Lancet 1997; 350: 1734-1737.

16 Wassertheil-Smoller S, Psaty B, Greenland P, Oberman A, Kotchen T, Mouton C, Black H, Aragaki A, Trevisan M. Association between cardiovascular outcomes and antihypertensive drug treatment in older women. JAMA 2004; 292: 2849-2859.

17 Buter H, Hemmelder MH, van Paassen P, Navis G, de Zeeuw D, de Jong PE. Is the antiproteinuric response to inhibition of the renin-angiotensin system less effective during the night? Nephrol Dial Transplant 1997; 12 (Suppl 2), 53-56.

18 Uzu T, Ishikawa K, Fujii T, Nakamura S, Inenaga T, Kimura G. Sodium restriction shifts circadian rhythm of blood pressure from nondipper to dipper in essential hypertension. Circulation 1997; 96: 1859-1862.

19 Uzu T, Kimura G. Diuretics shift circadian rhythm of blood pressure from nondipper to dipper in essential hypertension. Circulation 1999; 12: 1635-1638.

20 Skalska A, Gasowski J, Stepniewski M, Grodzicki T. Antioxidative protection in hypertensive patients treated with diuretics. Am J Hypertens 2005; 18: 1130-1132.

21 Lea J, Greene T, Hebert L, Lipkowitz M, Massry S, Middleton J, Rostand SG, Miller E, Smith W, Bakris GL. The relationship between magnitude of proteinuria reduction and risk of end-stage renal disease: results of the African American study of kidney disease and hypertension. Arch Intern Med 2005; 25: 947-953.

22 Kannel WB, Stampfer MJ, Castelli WP, Verter J. The prognostic significance of proteinuria: the Framingham study. Am Heart J 1984; 108: 1347-1357.

23 De Leeuw PW, Thijs L, Birkenhäger WH, Voyaki SM, Efstratopoulos AD, Fagard RH Leonetti G, Nachev C, Petrie JC, Rodicio JL, Rosenfeld JJ, Sarti C, Staessen JA for the Systolic Hypertension in Europe (Syst-Eur) Trial Investigators. Prognostic significance of renal function in elderly patients with isolated systolic hypertension: results from the Syst-Eur trial. J Am Soc Nephrol 2002; 13: 2213-2222.

24 Remuzzi G, Chiurchiu C, Ruggenenti P. Proteinuria predicting outcome in renal disease: nondiabetic nephropathies (REIN). Kidney Int 2004; 66(Suppl 92), S90-S96.

25 Shidham G, Hebert LA. Timed urine collections are not needed to measure urine protein excretion in clinical practice. Am J Kidney Dis 2006; 47: 8-14.

26 Gai M, Motta D, Giunti S, Fop F, Masini S, Mezza E, Segoloni GP, Lanfranco G. Comparison between $24-h$ proteinuria, urinary protein/creatinine ratio and dipstick test in patients with nephropathy: patterns of proteinuria in dipstick-negative patients. Scand J Clin Lab Invest 2006; 66: 299-307.

27 Gaspari F, Perico N, Remuzzi G. Timed urine collections are not needed to measure urine protein excretion in clinical practice. Am J Kidney Dis 2006; 47: 1-7.

28 National Kidney Foundation. DOQI clinical practice guidelines for chronic kidney disease: evaluation, classification, and stratification: Guideline 5. Assessment of proteinuria. Am J Kidney Dis 2002; 39(Suppl 2), S93-S102. 